\title{
ERP Implementation in an Indian Context: Examining Perceptions on Success Factors
}

\author{
Yogesh K. Dwivedi ${ }^{1}$, Raghav Sukumar ${ }^{2}$, Anastasia Papazafeiropoulou ${ }^{3}$, \\ and Michael D. Williams ${ }^{1}$ \\ ${ }^{1}$ School of Business and Economics, Swansea University, Swansea, SA2 8PP, UK \\ Tel.: +44 (0) 1792 602340, +4401792 295181 \\ ykdwivedi@gmail.com, \\ m.d.williams@swansea.ac.uk \\ ${ }^{2}$ Business \& Decision, 8th Floor, 55 Old Broad Street, London, EC2M 1RX, UK \\ Tel.: +44 (0) 2079976060 \\ sukumar.raghavegmail.com \\ ${ }^{3}$ Department of IS \& Computing, Brunel University, Uxbridge, UB8 8PP, UK \\ Tel.: +44 (0) 1895266035 \\ Anastasia.Papazafeiropoulou@brunel.ac.uk
}

\begin{abstract}
This research aims to explore factors responsible for successful implementation of ERP systems in Indian organizations. The paper also aims to explore the similarities and differences in ERP system adoption between locally-owned and multinational companies in India. The data was collected from 56 project managers and business analysts with ERP expertise from both locally-owned Indian and multinational companies. The findings suggest that Business Plan and Vision, Project Management and Top Management Support were perceived as the three most important factors responsible for successful implementation. The result revealed no significant differences between Indian and multinational companies, hence indicating that both types of firms undertake the ERP implementations in the same manner.
\end{abstract}

Keywords: ERP, Implementation Factors, Locally-owned Indian Organizations, Multinational Organizations.

\section{Introduction}

ERP is widely implemented by organisations in developed countries and is considered as the backbone of E-business (Al-Mashari et al. 2001; Rajapakse and Seddon 2005). However, its implementation is less prevalent in the developing countries context. Although India is considered an important provider of IT services to other countries, its own organizations are comparatively slower in technology adoption. Considering India's position in IT development and the fact that it is a developing country, this study aims to examine the implementation of ERP systems in an Indian context. There have been numerous studies listing the critical success factors (CSF) for successful ERP system implementation for developed countries. However, very few 
studies have examined these factors from a developing country perspective and have compared the factors from locally-owned and multinational companies.

This paper therefore aims to explore factors responsible for successful implementation of ERP systems in an Indian context. The paper also aims to explore the similarities and differences in ERP system adoption between locally-owned and multinational companies in India.

The remaining paper is organized as follows: The next section will provide an overview of the research method utilized. The findings will then be presented and discussed in subsequent sections. The last section of this paper will outline the conclusions.

\section{Research Method}

To achieve the specified research aim, this research considered survey as an appropriate method to collect data on factors important for implementation of ERP in an Indian context. Considering the research context, it was decided to collect data from project managers and business analysts from Indian organisations that have experienced ERP implementation process. These are the two positions which play key roles in the ERP implementation process and generally are proficient in both business and technical knowledge. A total of 56 responses were received from contacted organisations.

\subsection{Survey Questionnaire}

Based on factors identified from a systematic literature review there were fourteen questions (representing 14 success factors listed in Table 5) in the questionnaire. The questions were Likert scale type and were designed to examine the respondents' perception of the importance of different factors (adapted from Arunthari and Hasan 2005; Ehie and Madsen 2005; Nah et al. 2003) that determines successful implementation of ERP in Indian organisations. The respondents were requested to rate each of the factors on a five-point scale: " 1 = Neither critical nor important for success"; "2 = important but not critical/necessary for success"; "3 = somewhat critical and important for success"; "4 = critical and important for success"; "5 = extremely critical and important for success". The fourteen success factors included in the questionnaire are listed in Table 5. The first twelve factors are adapted from Nah et al. (2003), Cost/Budget from Ehie and Madsen (2005) and Vendor Selection from Arunthari and Hasan (2005).

\section{Findings}

\subsection{Demography of Profile of Respondents}

Considering the responses from an organization type perspective, as shown in Table 1, out of the total 56 responses, 41.1 percent $($ Count $=23)$ were locally-owned Indian companies and 58.9 percent $($ Count $=33)$ were from multinational companies in India. 
Table 1. Organization Types: Locally-owned Indian vs. Multinational Companies

\begin{tabular}{|l|c|c|}
\hline Organization Type & Frequency & Percent \\
\hline Indian Companies & 23 & 41.1 \\
\hline Multinational Companies & 33 & 58.9 \\
\hline Total & 56 & 100.0 \\
\hline
\end{tabular}

Considering the responses from the perspective of type of position held (by the respondent), as shown in Table 2, the total of 56 responses have been split into almost equal halves with 51.8 percent $($ Count $=29)$ coming from project managers and 48.2 percent $($ Count $=27)$ coming from business analysts.

Table 2. Respondent Types: Project Managers vs. Business Analysts

\begin{tabular}{|l|c|c|}
\hline Respondent Type & Frequency & Percent \\
\hline Project Manager & 29 & 51.8 \\
\hline Business Analyst & 27 & 48.2 \\
\hline Total & 56 & 100.0 \\
\hline
\end{tabular}

Consolidating Table 1 and Table 2 gives a cross tabulation of both organization type and respondent type to better understand the break-up of the responses as shown in Table 3. The number of responses from project managers from locally-owned Indian companies and multinational companies are almost equal with 14 and 15 respectively. The number of responses from business analysts in multinational companies is 18 , which is twice the number that came from Indian companies (see Table 4).

\subsection{Descriptive Statistics: Importance of Examined Factors}

Table 4 illustrates the number of responses, the mean score and the standard deviation for each of the identified success factors. It is evident from Table 5 that F2 (Business Plan and Vision), F10 (Project Management) and F12 (Top Management Support) are the three most important success factors as perceived by project managers and business analysts regarding the implementation of ERP systems (see Table 4).

The $\mathrm{t}$ - test for equality of means for organization type (see Table 5) indicates that there is no significant difference in the perceptions of the success factors between the two types of companies. Among the 14 success factors, there is not a single factor with s significance value less than or equal to 0.05 . This indicates that locally-owned Indian companies are weighing ERP implementation projects in the same lines as multinational companies. 
Table 3. Organization Type and Respondent Type: Cross Tabulation

\begin{tabular}{|l|c|c|c|c|}
\hline \multirow{2}{*}{ Organization Type } & \multirow{2}{*}{} & \multicolumn{3}{|c|}{ Respondent Type } \\
\cline { 3 - 5 } & & $\begin{array}{c}\text { Project } \\
\text { Manager }\end{array}$ & $\begin{array}{c}\text { Business } \\
\text { Analyst }\end{array}$ & Total \\
\hline \multirow{2}{*}{$\begin{array}{l}\text { Locally-owned Indian } \\
\text { Companies }\end{array}$} & Count & 14 & 9 & 23 \\
\cline { 2 - 5 } & $\begin{array}{c}\% \text { of } \\
\text { Total }\end{array}$ & $25.0 \%$ & $16.1 \%$ & $41.1 \%$ \\
\hline \multirow{3}{*}{ Multinational Companies } & Count & 15 & 18 & 33 \\
\cline { 2 - 5 } & $\begin{array}{c}\% \text { of } \\
\text { Total }\end{array}$ & $26.8 \%$ & $32.1 \%$ & $58.9 \%$ \\
\hline \multirow{2}{*}{ Total } & Count & 29 & 27 & 56 \\
\cline { 2 - 5 } & $\begin{array}{c}\% \text { of } \\
\text { Total }\end{array}$ & $51.8 \%$ & $48.2 \%$ & $100.0 \%$ \\
\hline
\end{tabular}

Table 4. Descriptive Statistics of the 14 Success Factors

\begin{tabular}{|c|c|c|c|c|}
\hline \multicolumn{2}{|l|}{ Factors } & $\mathrm{N}$ & Mean & S.D. \\
\hline Business Plan and Vision & $\mathrm{F} 2$ & 56 & 4.52 & .786 \\
\hline Project Management & F10 & 56 & 4.25 & .769 \\
\hline Top Management Support & F12 & 56 & 4.21 & .986 \\
\hline Software Development, Testing and Troubleshooting & F11 & 56 & 4.16 & .804 \\
\hline Cost / Budget & F13 & 56 & 4.09 & .959 \\
\hline Vendor Selection & $\mathrm{F} 14$ & 56 & 4.09 & .996 \\
\hline Effective Communication & F6 & 56 & 3.98 & .842 \\
\hline User Training and Education & F5 & 56 & 3.89 & .947 \\
\hline Business Process Reengineering & $\mathrm{F} 3$ & 56 & 3.73 & .842 \\
\hline ERP Teamwork and Composition & F7 & 56 & 3.66 & .815 \\
\hline $\begin{array}{l}\text { Appropriate Business and Information Technology (IT) } \\
\text { Legacy Systems }\end{array}$ & $\mathrm{F} 1$ & 56 & 3.62 & .983 \\
\hline Change Management Culture & $\mathrm{F} 4$ & 56 & 3.54 & .972 \\
\hline Project Champion & F9 & 56 & 3.48 & .972 \\
\hline Monitoring and Evaluation of Performance & $\mathrm{F} 8$ & 56 & 3.43 & .912 \\
\hline
\end{tabular}


Table 5. Group Statistics and t - test for Organization Type and Success Factors

\begin{tabular}{|c|c|c|c|c|c|c|c|}
\hline \multirow{2}{*}{ FACTORS } & \multirow{2}{*}{$\begin{array}{c}\text { Organization } \\
\text { Type }\end{array}$} & \multirow{2}{*}{$\mathrm{N}$} & \multirow{2}{*}{ Mean } & \multirow{2}{*}{$\begin{array}{c}\text { Std. } \\
\text { Deviation }\end{array}$} & \multicolumn{3}{|c|}{$\begin{array}{l}\text { t-test for Equality of Means for } \\
\text { Organization Type }\end{array}$} \\
\hline & & & & & $\mathrm{t}$ & df & $\begin{array}{c}\text { Sig. } \\
\text { (2-tailed) }\end{array}$ \\
\hline \multirow{2}{*}{$\mathrm{F} 1$} & $\mathrm{IC}$ & 23 & 3.57 & 1.080 & \multirow{2}{*}{-.377} & \multirow{2}{*}{54} & \multirow{2}{*}{.708} \\
\hline & $\mathrm{MN}$ & 33 & 3.67 & .924 & & & \\
\hline \multirow{2}{*}{$\mathrm{F} 2$} & IC & 23 & 4.70 & .559 & \multirow{2}{*}{1.426} & \multirow{2}{*}{54} & \multirow{2}{*}{.160} \\
\hline & $\mathrm{MN}$ & 33 & 4.39 & .899 & & & \\
\hline \multirow{2}{*}{ F3 } & IC & 23 & 3.83 & .576 & \multirow{2}{*}{.694} & \multirow{2}{*}{54} & \multirow{2}{*}{.491} \\
\hline & $\mathrm{MN}$ & 33 & 3.67 & .990 & & & \\
\hline \multirow{2}{*}{$\mathrm{F} 4$} & IC & 23 & 3.61 & .988 & \multirow{2}{*}{.466} & \multirow{2}{*}{54} & \multirow{2}{*}{.643} \\
\hline & $\mathrm{MN}$ & 33 & 3.48 & .972 & & & \\
\hline \multirow{2}{*}{ F5 } & IC & 23 & 4.04 & .706 & \multirow{2}{*}{.993} & \multirow{2}{*}{54} & \multirow{2}{*}{.325} \\
\hline & $\mathrm{MN}$ & 33 & 3.79 & 1.083 & & & \\
\hline \multirow{2}{*}{ F6 } & IC & 23 & 3.96 & .767 & \multirow{2}{*}{-.188} & \multirow{2}{*}{54} & \multirow{2}{*}{.851} \\
\hline & $\mathrm{MN}$ & 33 & 4.00 & .901 & & & \\
\hline 57 & IC & 23 & 3.52 & .665 & & & \\
\hline 17 & $\mathrm{MN}$ & 33 & 3.76 & .902 & -1.000 & 54 & .291 \\
\hline$\Gamma 0$ & IC & 23 & 3.26 & 1.054 & 1152 & 54 & 254 \\
\hline 10 & $\mathrm{MN}$ & 33 & 3.55 & .794 & 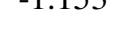 & 34 & .234 \\
\hline & IC & 23 & 3.39 & .783 & & & \\
\hline 17 & $\mathrm{MN}$ & 33 & 3.55 & 1.092 & -.500 & 34 & .504 \\
\hline 510 & IC & 23 & 4.48 & .593 & 1800 & 54 & $06 ?$ \\
\hline 110 & $\mathrm{MN}$ & 33 & 4.09 & .843 & 1.093 & 34 & (0) \\
\hline E11 & IC & 23 & 4.17 & .576 & 107 & 54 & 010 \\
\hline 111 & $\mathrm{MN}$ & 33 & 4.15 & .939 & .102 & 34 & (1919. \\
\hline D & IC & 23 & 4.43 & .788 & 110 & 54 & 164 \\
\hline 112 & $\mathrm{MN}$ & 33 & 4.06 & 1.088 & 1.71 & דנה & דואו \\
\hline$\Gamma 12$ & IC & 23 & 4.09 & .733 & & & 000 \\
\hline 515 & $\mathrm{MN}$ & 33 & 4.09 & 1.100 & -.015 & 34 & .900 \\
\hline 5 & IC & 23 & 4.35 & .832 & 617 & 54 & 0 \\
\hline 154 & $\mathrm{MN}$ & 33 & 3.91 & 1.071 & 1.047 & 34 & .100 \\
\hline
\end{tabular}




\section{Discussion}

Many organizations in developing countries may not be able to invest the initial cost of ERP implementations (Rajapakse and Seddon 2005). Hence cost is a critical success factor which needs to be considered during the start or proposal of ERP projects. In terms of a project, the business case should reflect rigorous cost benefit analysis to clearly illustrate viability of the project and to convince and gain management support. Top management support in terms of resource remittance and making major decisions is very crucial during ERP implementations (Al-Mashari et al. 2001). Considering the low regulation levels and unconventional business processes, it may be a challenge to find an appropriate fit between the business process and the ERP system, hence the business process re-engineering becomes crucial (Rajapakse and Seddon 2005). Training and education is an important factor and it may need extra emphasis in developing countries where ERP knowledge is less for end users (Rajapakse and Seddon 2005). The best human resources when used effectively lead to a successful implementation of ERP projects. Hence the composition and teamwork of an ERP project must be given importance and it is recommended that managers do not compromise on technical expertise when assigned to the project. Vendor selection is another fundamental key to success because a wrong decision in choosing a vendor may lead to aligning issues of the business process and the ERP system (Arunthari and Hasan 2005). "Software development, testing and troubleshooting" and "Monitoring and evaluation of performance" should run parallel as they are closely associated. However, the finding from Table 5 reveals that the level of importance given to software development, testing and troubleshooting is much higher than monitoring and evaluation of performance. The reason may be because India is one of the largest outsourcing hubs for IT development and the importance of software development has become a part of the culture. According to the findings, a business plan and vision are considered the most critical and important ingredients for success (Table 5). This study recommends that managers must make sure that the business plan and vision are transparent to all the members of the team. A successful ERP implementation is possible only if all the contributing members have a common business vision and goal.

\section{Conclusions}

This study made an initial attempt to understand the adoption of Enterprise Resource Planning Systems in an Indian context. The success factors identified from the literature review were rated on the level of criticality and importance of success by project managers and business analysts from locally-owned Indian companies and multinational companies in India. The findings illustrate that Business Plan and Vision, Project Management, Top Management Support, Software Development, Cost/Budget and Vendor Selection are the factors that play the most important role in ERP implementation. The results also revealed that there was no significant difference in the perception towards the success factors between locally-owned Indian companies and multinational companies. This information may be considered useful when locally-owned Indian companies and firms outside decide to implement ERP 
systems. However, there existed a significant difference in the level of importance given to two of the fourteen success factors by project managers and business analysts.

\section{References}

Al-Mashari, M., Al-Mudimigh, A., Zairi, M.: ERP implementation: An integrative methodology. European Journal of Information Systems 10(4), 216 (2001)

Arunthari, S., Hasan, H.: ERP System Adoption and Vendor Selection by Locally-owned and Multinational Companies in Thailand. In: Proceeding of Pacific Asia Conference on Information Systems (2005), http: / /www . pacis-net. org/file/2005/241.pdf

Ehie, I.C., Madsen, M.: Identifying critical issues in enterprise resource planning (ERP) implementation. Computers in Industry 56(6), 545-557 (2005)

Nah, F.F.H., Zuckweiler, K.M., Lau, J.L.S.: ERP implementation: Chief Information Officers perceptions of critical success factors. International Journal of Human-Computer Interaction 16(1), 5-22 (2003)

Rajapakse, J., Seddon, P.B.: Why ERP may not be suitable for organizations in developing countries in Asia. In: Proceedings of PACIS, pp. 1382-1388 (2005) 